\title{
Causes and characteristics of death in ICU: a national study
}

\author{
JC Orban ${ }^{1 *}$, Y Walrave ${ }^{1}$, M Leone ${ }^{2}$, B Allaouchiche ${ }^{3}$, JY Lefrant $^{4}$, JM Constantin ${ }^{5}$, S Jaber ${ }^{6}$, C Ichai $^{1}$, \\ AzuRea study group
}

From ESICM LIVES 2015

Berlin, Germany. 3-7 October 2015

\section{Introduction}

Mortality of ICU patients is a global parameter reported as an end-point in numerous studies. However, causes and characteristics of patients' death are studied only in particular pathologies such as sepsis, cardiac arrest or ARDS ([1,2]).

\section{Objectives}

The aim of our study was to analyse causes and circumstances of death in a general ICU population.

\section{Methods}

We performed a prospective observational study. Every ICU included all death occurring during a month randomised in the year of the study. Demographic data were collected as well as circumstances of death (organ failure and organ support at this time). An organ failure was defined by a SOFA sub-score $\geq 3$. Population of the study was dichotomised in expected death (following withholding or withdrawal of care, or brain death) and unexpected death (following maximal intensity of care). Data are expressed as median and IQR. Comparisons were made by a Mann-Whitney or chi-squared tests as appropriate. A p value $<0.05$ was considered as statistically significant.

\section{Results}

Ninety-six ICUs included 698 dead patients during the study time. Main characteristics of the population and their comparison between expected $(n=473)$ and unexpected deaths $(\mathrm{n}=225)$ are reported in the table.

At the time of death, $586(84 \%)$ patients presented at least one organ failure: cardiovascular (58\%), respiratory $(31 \%)$, renal $(33 \%)$, neurologic $(30 \%)$, liver $(8 \%)$
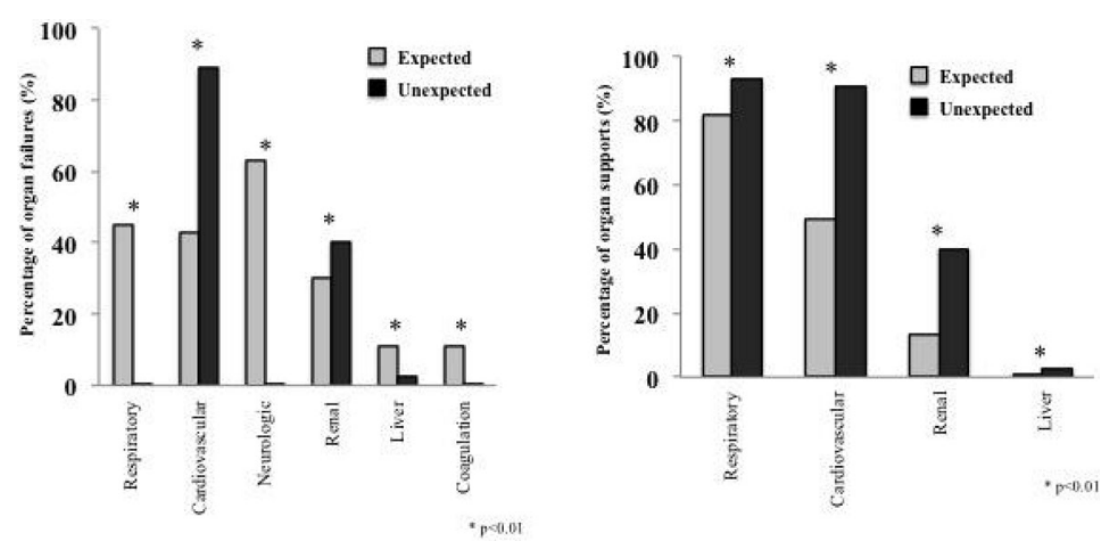

Figure 1 Percentages of organ failures and support.

${ }^{1}$ Nice University Hospital, Medical Surgical ICU, Nice, France

Full list of author information is available at the end of the article

(c) 2015 Orban et al.; This is an Open Access article distributed under the terms of the Creative Commons Attribution License (http:// creativecommons.org/licenses/by/4.0), which permits unrestricted use, distribution, and reproduction in any medium, provided the original work is properly cited. 
Table 1. Demographic data of the population

\begin{tabular}{lllll}
\hline & Population of the study & Expected death $(\mathbf{n}=\mathbf{4 7 3})$ & Unexpected death $(\mathbf{n}=\mathbf{2 2 5})$ & $\mathbf{p}$ values \\
\hline Age (years) & $69[57-78]$ & $69[57-78]$ & $68[56-77]$ & 0.32 \\
\hline SAPS II & $63[48-83]$ & $60[47-76]$ & $77[52-93]$ & $<0.001$ \\
\hline SOFA score & $11[7-13]$ & $10[7-13]$ & $12[9-15]$ & $<0.001$ \\
\hline Admission causes & & & & $<0.001$ \\
\hline Cardiovascular & $193(28 \%)$ & $103(22 \%)$ & $90(40 \%)$ & 0.50 \\
\hline Respiratory & $182(26 \%)$ & $127(27 \%)$ & $55(24 \%)$ & $<0.001$ \\
\hline Neurologic & $169(24 \%)$ & $149(32 \%)$ & $20(9 \%)$ & 0.28 \\
\hline Miscellaneous & $154(22 \%)$ & $94(19 \%)$ & $60(27 \%)$ & $<0.001$ \\
\hline Length of stay $(\mathrm{d})$ & $3[1-10]$ & $5[2-12]$ & $10-8]$ & \\
\hline
\end{tabular}

and coagulation (8\%). At the same time, an organ support was used in 440 (63\%) patients: catecholamines (63\%), mechanical ventilation $(85 \%)$, renal replacement therapy (28\%) and liver dialysis (1\%). Comparison of these parameters between groups is reported in the figure.

\section{Conclusions}

Patients who died in ICU presented, most of the time, at least one organ failure. Expected death patients exhibited more neurologic and respiratory failures whereas cardiovascular failure was more prominent in unexpected death. In the latter group of patients, the proportion of organ support was higher corresponding to a greater intensity of care.

\section{Authors' details}

${ }^{1}$ Nice University Hospital, Medical Surgical ICU, Nice, France. ${ }^{2}$ APHM Hôpital Nord, Anesthesia and Intensive Care Department, Marseille, France. ${ }^{3}$ Hospices Civils de Lyon, Anesthesia and Intensive Care Department, Lyon, France.

${ }^{4}$ Nimes University Hospital, Anesthesia and Intensive Care Department, Nîmes, France. ${ }^{5}$ Clermont-Ferrand University Hospital, Anesthesia and Intensive Care Department, Clermont-Ferrand, France. ${ }^{6}$ Montpellier University Hospital, Anesthesia and Intensive Care Department, Montpellier, France.

Published: 1 October 2015

\section{References}

1. Lancet Respir Med 2014, 2:380-6.

2. Intensive Care Med 2013, 39:1972-80.

doi:10.1186/2197-425X-3-S1-A770

Cite this article as: Orban et al:: Causes and characteristics of death in ICU: a national study. Intensive Care Medicine Experimental 2015 3(Suppl 1): A770.

\section{Submit your manuscript to a SpringerOpen ${ }^{\circ}$ journal and benefit from:}

- Convenient online submission

- Rigorous peer review

- Immediate publication on acceptance

- Open access: articles freely available online

- High visibility within the field

- Retaining the copyright to your article

Submit your next manuscript at $>$ springeropen.com 